DOI: $10.20396 /$ cel.v62i0. 8660380

\title{
A DIVULGAÇÃO DA FILOSOFIA NAS REVISTAS PHILOSOPHIE MAGAZINE E FILOSOFIA CIÊNCIA \& VIDA
}

\section{LA VULGARISATION DE LA PHILOSOPHIE DANS PHILOSOPHIE MAGAZINE ET FILOSOFIA CIÊNCIA \& VIDA}

\author{
DANIELA NIENKÖTTER SARDÁ ${ }^{1}$
}

\begin{abstract}
RESUMO: O artigo tem como objetivo apresentar os resultados da comparação de discursos de revistas de divulgação da filosofia. Mais precisamente, o corpus analisado é composto pelo gênero "artigo de capa", da revista francesa Philosophie Magazine e da revista brasileira Filosofia Ciência \& Vida, publicados entre 2006 e 2016. A metodologia empregada nas análises é a análise de discursos comparativa, e as categorias conceituais mobilizadas são as formas de transmissão do discurso alheio e, em menor medida, os dêiticos. Os resultados apontam para uma presença, na comunidade francesa, de divulgadores (no caso, de jornalistas) especializados em filosofia, ao passo que, na comunidade brasileira, ainda não se constata uma tal especialização, sendo a filosofia divulgada predominantemente por acadêmicos da área de ciências humanas. Tal especialização, na França, se deve a fatores sócio-econômicos e culturais, os quais favorecem o interesse e as condições do grande público para a aquisição de revistas de divulgação da filosofia; algo que ainda não ocorre no Brasil, onde essas revistas estão vinculadas à esfera didática, sendo distribuídas nas escolas públicas brasileiras.
\end{abstract}

Palavras-chave: análise de discursos comparativa; filosofia; revistas de filosofia; divulgação científica; formas de transmissão do discurso alheio.

RÉSUMÉ : L'article vise à présenter les résultats d'une comparaison de discours des magazines de vulgarisation de la philosophie. Plus précisément, le corpus analysé est composé du genre " article de couverture », du magazine français Philosophie Magazine et du magazine brésilien Filosofia Ciência \& Vida, parus entre 2006 et 2016. La méthodologie adoptée dans les analyses, c'est l'analyse du discours comparative, et les catégories conceptuelles mobilisées, ce sont les formes de transmission du discours d'autrui et, dans une moindre mesure, les déictiques. Les résultats pointent vers une présence, dans la communauté française, de vulgarisateurs (en l'occurrence, des journalistes) spécialisés en philosophie, tandis que, dans la communauté brésilienne, on ne constate pas une telle spécialisation ; la philosophie étant, par conséquent, vulgarisée surtout par des universitaires du domaine des sciences humaines. Une telle spécialisation, en France, est due à des facteurs socio-économiques et culturels, lesquels favorisent l'intérêt et les conditions du grand public pour l'acquisition de magazines de vulgarisation de la philosophie ; ce qui n'a pas encore lieu au Brésil, où ces magazines sont plutôt liées à la sphère didactique, étant distribuées dans les écoles publiques brésiliennes.

Mots-clés : analyse du discours comparative ; philosophie ; magazines de philosophie ; vulgarisation scientifique ; formes de transmission du discours d'autrui.

\footnotetext{
${ }^{1}$ Pós-doutoranda na Universidade de São Paulo (USP), São Paulo, SP, Brasil; bolsista da FAPESP (Proc. n 2017/123068); danielasarda@usp.br

Orcid: https://orcid.org/0000-0002-7128-2469.
}

Cad. Est. Ling., Campinas, v.62, p. 1-15, e020020, 2020 


\section{INTRODUÇÃO}

A divulgação científica tem sido objeto de diversos estudos recentemente, tanto no Brasil quanto no exterior. Somente numa perspectiva discursiva, diversas são as abordagens de um mesmo fenômeno, conforme o mostram Grillo, Giering e Motta-Roth (2016). Entretanto, ainda na perspectiva discursiva, encontramos poucos estudos sobre a divulgação da filosofia. Tendo em vista esse fato, decidimos estudar a divulgação da filosofia tal como ela é abordada em revistas endereçadas ao grande público. A especificidade do presente estudo, no entanto, é a análise comparativa daquela, compreendendo duas línguas e culturas diferentes: a francesa e a brasileira. Para tanto, foram escolhidas duas revistas cuja circulação é respectivamente importante nos dois países, estando no mercado desde o ano de 2006 até hoje, a saber, as revistas Philosophie Magazine e Filosofia Ciência \& Vida.

$\mathrm{Na}$ seção sobre a metodologia, abordaremos com mais detalhes a análise de discursos comparativa, pois as análises aqui feitas serão norteadas por essa vertente. Por ora, é importante observar que o objetivo da análise de discursos comparativa é comparar textos de um mesmo gênero de discurso em duas (ou mais) línguas-culturas diferentes. Essa corrente teve início na França, mais precisamente no laboratório CEDISCOR (Centre de recherche sur les discours ordinaires et spécialisés), da Université Sorbonne Nouvelle - Paris 3, e hoje vem sendo trabalhada e adaptada na Universidade de São Paulo, de um ponto de vista predominantemente bakhtiniano. Como o mostram Grillo e Glushkova (2016), já em Bakhtin havia uma preocupação em comparar e compreender diferentes culturas.

Com este artigo, pretendemos apresentar resultados da nossa pesquisa de pós-doutorado em andamento, cujo projeto visa contribuir para a implementação da análise de discursos comparativa no Brasil. As análises de discurso comparativas aqui apresentadas dizem respeito, mais precisamente, ao estudo que realizamos de um corpus composto pelos artigos de capa da revista francesa Philosophie Magazine (doravante PM) e da revista brasileira Filosofia Ciência \& Vida (doravante $F C \& V$ ), publicadas entre os anos de 2006 e 2016. A análise linguística do corpus parte da observação dos dêiticos e das formas de transmissão do discurso alheio presentes no discurso dessas revistas, com o objetivo de investigar a maneira como a filosofia é nelas divulgada. Ao final da pesquisa de pós-doutorado, o nosso objetivo é saber mais sobre como a filosofia é representada nessas revistas, o que nos ajudará a determinar como a filosofia é representada na França e no Brasil. $\mathrm{O}$ artigo apresenta a seguinte estrutura: finalizada a presente introdução (seção 1), apresentaremos a metodologia (seção 2) e a seleção do corpus (seção 3) referente às análises comparativas realizadas na seção 4 deste artigo, que terão como foco as formas de transmissão do discurso alheio e os dêiticos, sendo divididas em dois momentos, um consagrado à revista francesa $P M$ (seção 4.1) e outro à revista brasileira $F C \& V$ (seção 4.2). Uma seção com a conclusão (seção 5) e outra com as referências constam ao final do artigo.

\section{UMA ANÁLISE COMPARATIVA DE DISCURSOS DE DIVULGAÇÃO CIENTÍFICA}

A metodologia adotada segue os princípios da análise de discursos comparativa, tal como ela vem sendo retrabalhada no Brasil atualmente. Além disso, adotaremos o ponto de vista da divulgação científica proposto por Grillo (2013), qual seja, "tomada como uma modalidade de relação dialógica [...] estando, por isso, sujeita às influências da situação imediata de comunicação e do contexto sócio-histórico mais amplo" (p. 55). Nessa perspectiva, o discurso 
de divulgação científica procura "criar uma cultura científica no destinatário" (GRILLO; GIERING; MOTTA-ROTH, 2016, p. 11). Trata-se, pois, de um ponto de vista com foco na metalinguística bakhtiniana. Como lembra Combettes (1989, p. 114), "não se pode fazer abstração, para Bakhtin, da dimensão dialogal: toda enunciação leva em conta o destinatário, mesmo se esse destinatário não é um indivíduo 'preciso', mas uma coletividade mais ou menos vaga" 2 . Eis por que empregamos, nas análises aqui apresentadas, duas categorias de análise que favorecem a investigação dessa relação com o destinatário: os dêiticos e a categoria conceitual da transmissão do discurso alheio. Durante as análises, mostraremos como essas duas categorias se complementam e, em alguns pontos, como a análise da transmissão do discurso alheio, de um ponto de vista sociológico, à maneira de Volóchinov (2018 [1929]), nos permite observar aspectos que a análise dos dêiticos sozinha não nos permitiria analisar.

Em linhas gerais, o método da análise de discursos comparativa - tal como ela surgiu no laboratório CEDISCOR (Centre de recherche sur les discours ordinaires et spécialisés), da Université Sorbonne Nouvelle - segue aquele da análise do discurso em geral. Portanto, num primeiro momento, procede-se a uma "descrição da materialidade linguística dos discursos sem descrição, não nos situaríamos em uma perspectiva linguística - e a uma interpretação dos dados coletados - sem interpretação, o procedimento não seria do domínio da $\mathrm{AD}$ [análise do discurso]"3 (CLAUDEL et al., 2013, p. 22). Para von Münchow (2013), a finalidade da análise de discursos comparativa é, mais especificamente, "a comparação de diferentes culturas discursivas, noção que abrange as manifestações discursivas das representações sociais em circulação em uma dada comunidade sobre os objetos no sentido amplo, por um lado, e sobre os discursos a se manter sobre esses objetos, por outro lado" (VON MÜNCHOW, 2013, p. 86) 4 $^{\text {. Ao }}$ final do nosso estudo de pós-doutorado, esperamos depreender as representações sociais da filosofia, tanto na França quanto no Brasil. As análises abaixo (seção 4) já apontam pistas bastante relevantes a esse respeito.

No que concerne à análise de textos de divulgação científica, Grillo, Giering e Motta-Roth (2016), num editorial intitulado "Perspectivas discursivas da divulgação/popularização da ciência", apresentam as diferentes perspectivas teóricas nas quais os textos de divulgação científica são analisados. Nos estudos da linguagem, a perspectiva mais corrente é a que visa a divulgação científica como uma "tradução ou reformulação do discurso científico" (p. 4). Outras abordagens também são sintetizadas pelas autoras; por exemplo, a que considera a divulgação científica como uma "modalidade particular de relação dialógica" (p. 4); é essa que adotaremos aqui. Embora, neste trabalho, tenhamos analisado os textos de divulgação científica segundo uma abordagem dialógica, é preciso notar que esse não é o enfoque predominante na França, país onde surgiu a análise de discursos comparativa. Na França, é mais comum que os discursos de divulgação científica sejam analisados como uma reformulação do discurso científico; o enfoque é mais linguístico, cabendo ao analista observar quais são as marcas (linguísticas, enunciativas, discursivas) dessa reformulação. No presente momento da nossa pesquisa de pósdoutorado, estamos refletindo sobre as maneiras de acomodar a abordagem francesa com a

\footnotetext{
2 No original: "on ne peut faire abstraction, pour Bakhtine, de la dimension dialogale : toute énonciation tient compte du destinataire, même si ce destinataire n'est pas un individu 'précis', mais une collectivité plus ou moins vague". As traduções dos excertos em francês, ao longo de todo o artigo, são de nossa autoria.

${ }^{3}$ No original: "description de la matérialité linguistique des discours - sans description, on ne se situerait pas dans une perspective linguistique - et à une interprétation des données rassemblées - sans interprétation, la démarche ne relèverait pas de l'AD".

${ }^{4}$ No original: "la comparaison de différentes cultures discursives, notion qui recouvre les manifestations discursives des représentations sociales circulant dans une communauté donnée sur les objets au sens large, d'une part, et sur les discours à tenir sur ces objets, d'autre part".
}

Cad. Est. Ling., Campinas, v.62, p. 1-15, e020020, 2020 
abordagem bakhtiniana. Num artigo recente (SARDÁ, 2021), partimos da noção de categoria de análise a fim de melhor explorarmos essa questão. Vimos que, na França, a análise de discursos comparativa parte, desde o seu surgimento, da busca de categorias (linguísticas, enunciativas e discursivas) comparáveis. Já na perspectiva bakhtiniana, da análise dialógica de discursos, o estabelecimento de categorias a priori não é aconselhado (cf. BRAIT, 2018) ${ }^{5}$. Isso não significa que a análise de discursos comparativa de inspiração bakhtiniana não considere as marcas linguísticas. Tanto é assim que analisaremos dêiticos e as marcas da transmissão do discurso alheio nos discursos do nosso corpora. É o papel dado a essas categorias durante a análise que será diferente numa análise de discursos comparativa segundo essa abordagem, conforme veremos neste artigo.

Por outro lado, a análise de discursos comparativa, conforme já anunciado na introdução deste texto, compara textos de um mesmo gênero de discurso em duas (ou mais) línguasculturas diferentes. Em outras palavras, é o gênero que serve de tertium comparationis na análise de discursos comparativa, ou seja, a invariante que garante a comparação entre textos oriundos de duas línguas-culturas distintas. Sob esse aspecto, há convergência com a perspectiva dialógica da divulgação científica, para a qual "o conceito de gênero discursivo é central para a descrição e a interpretação das diversas modalidades de circulação da ciência, por permitir uma metodologia que, sem perder a natureza linguística, articule conceitos de diversas ordens" (GRILLO, 2013, p. 12).

Antes de darmos prosseguimento a este artigo, é importante ressaltar que o domínio da análise de discursos comparativa está em plena construção no Brasil. Embora, aqui, ele venha sendo abordado num quadro bakhtiniano, a influência de autores franceses se faz sentir, ainda, de modo bastante evidente.

\section{A SELEÇÃO DE UM CORPUS DE REVISTAS DE DIVULGAÇÃO DA FILOSOFIA}

A fim de dar continuidade a um estudo que já havíamos começado no doutorado sobre as representações da filosofia na França e no Brasil (cf. SARDÁ, 2015), pesquisa cujo corpus envolveu textos da esfera didática, decidimos tratar, num pós-doutorado, da divulgação dessa mesma disciplina nas mesmas línguas-culturas outrora analisadas. Para tanto, as revistas $P M$ e $F C \& V$ apareceram como um corpus relevante para essa abordagem, pois ambas as revistas surgiram no mesmo ano nos dois países (em 2006) e têm como público-alvo os interessados pela filosofia (embora com particularidades próprias a cada país, conforme veremos na seção 4). $P M$ e $F C \& V$ passaram a constituir, portanto, o corpus de referência de nosso estudo de pósdoutorado; optamos pelo período de 2006 a 2016, de modo a investigar a consolidação dos respectivos periódicos no período de uma década; ainda que ambos continuem sendo publicados até hoje.

Mais precisamente, empregamos na seleção do nosso material a tipologia estabelecida por Rastier et Pincemin (1999) para dar conta da organização de um corpus. Segundo essa tipologia, todos os textos que existem sobre um determinado tema constituem o "corpus existente". Nesse sentido, todas as revistas de divulgação da filosofia existentes na França e no Brasil constituiriam o nosso corpus existente. Como seria impossível, naturalmente, realizarmos a coleta e a leitura de todos esses textos, montamos um "corpus de referência" que tem um estatuto de um "referencial representativo". No nosso caso, selecionamos duas revistas que nos

\footnotetext{
${ }^{5}$ Nosso estudo mostrou, no entanto, que a abordagem do CEDISCOR, embora procure categorias comparáveis, não o faz de modo mecânico (cf. SARDÁ, 2021).
} 
pareceram as mais relevantes em cada um dos dois países: na França, Philosophie Magazine, e no Brasil, Filosofia Ciência \& Vida. Trata-se das revistas que estão há mais tempo consolidadas no mercado editorial de cada país (ambas desde 2006 até hoje), a revista francesa é a revista de divulgação da filosofia mais popular ${ }^{6}$ no país (e até no exterior), e no Brasil, ainda que não tenhamos os dados de venda (assinalamos o motivo na seção 4 abaixo), sabemos que ela integra o Programa Nacional Biblioteca da Escola (PNBE periódicos), sendo distribuída nas escolas públicas brasileiras. Escolhemos abordar um recorte por década (2006-2016), conforme justificado acima.

Escolhemos um número de $P M$ e um número de $F C \& V$ para cada ano de circulação das revistas ${ }^{7}$. Nosso corpus de referência é composto, portanto, por 22 números. De $P M$, selecionamos os números 01 (abr.-maio 2006), 09 (maio. 2007), 20 (jun. 2008), 34 (nov. 2009), 39 (mai 2010), 45 (dez. 2010/jan. 2011), 59 (maio 2012), 65 (dez. 2012/jan. 2013), 79 (maio 2014), 88 (abr. 2015) e 95 (dez. 2015/jan. 2016). De $F C \& V$, selecionamos os números 03 (out. 2006), 15 (out. 2007), 20 (mar. 2008), 32 (mar. 2009), 53 (nov. 2010), 60 (jun. 2011), 67 (fev. 2012), 85 (ago. 2013), 90 (jan. 2014), 107 (jun. 2015) e 119 (ago. 2016) ${ }^{8}$.

Continuando a tipologia estabelecida por Rastier et Pincemin (1999), o corpus de trabalho diz respeito ao "conjunto de textos para os quais queremos obter uma caracterização"9 (n. p). Enfim, o "corpus de eleição" é um "sub-corpus do corpus de trabalho"10. Dessa forma, para o estudo apresentado neste artigo, partimos da observação de que, à primeira vista, a capa de ambas as revistas dava, em regra, origem a um artigo de divulgação científica e/ou a um dossiê (este constituído por diversos gêneros, como o próprio artigo, além de entrevistas com filósofos, respostas de filósofos a uma dada questão etc.). Haja vista que a análise de discursos comparativa trabalha com a comparação de um mesmo gênero de discurso em duas línguasculturas distintas, escolhemos nos fixar no gênero artigo de capa. Maingueneau (2019, p. 10), num estudo recente sobre o domínio filosófico, cita o divulgador e o ensaísta como os dois responsáveis por gerir relações com o universo exterior à filosofia propriamente dita; daí a importância, a nosso ver, de trabalhar a comparação do gênero "artigo de capa"11. Dessa forma, todos os artigos de capa das revistas que compõem o nosso corpus de referência integram o corpus de trabalho mobilizado neste artigo. Caso outros sub-corpus sejam organizados no interior desse corpus de trabalho, assinalaremos ao longo das análises.

\footnotetext{
${ }^{6}$ Além de ter um número de vendas considerável, conforme pode ser visto na tabela da seção 4 abaixo, a revista $P M$ obteve, em abril de 2010, “o prêmio Syndicat de la presse magazine et d'information de 'Revista do ano' assim como o de melhor revista na categoria "Cultura e descobertas" [No original: "Em avril 2010, le magazine obtient le prix Syndicat de la presse magazine et d'information du 'Magazine de l'année' ainsi que celui de meilleur magazine dans la catégorie "Culture et découvertes"'] Disponível em: https://fr.wikipedia.org/wiki/Philosophie_Magazine Acesso em: 04 jul. 2020.

${ }^{7}$ A escolha de um número por ano deu-se aleatoriamente, embora tennhamos variado a escolha de modo que os diversos meses do ano fossem levados em conta, garantindo, assim, a representatividade do corpus.

${ }^{8} \mathrm{O}$ número 7 (fev. 2007) de $F C \& V$ passou a integrar o nosso corpus após essa seleção; em caráter excepcional, pois trata de um tema crucial para a compreensão das revistas de filosofia no contexto brasileiro. Seu tema de capa é "Volta às aulas" e discute-se a obrigatoriedade do ensino da filosofia no Ensino Médio, que se tornou obrigatório no Brasil em 2008, com a Lei Federal no $11.684 / 08$.

${ }^{9}$ No original: "ensemble des textes pour lesquels on veut obtenir une caractérisation".

${ }^{10}$ No original: "sous-corpus du corpus de travail".

${ }^{11}$ Num primeiro momento, havíamos pensado em nomear esses textos "ensaios de capa", considerando, justamente, esse caráter mais ensaístico dos textos observados. Todavia, mudamos de ideia com o intuito de evitar confusões com os ensaios fotográficos, comuns em revistas de outros segmentos.
}

Cad. Est. Ling., Campinas, v.62, p. 1-15, e020020, 2020 


\section{ANÁlISE DAS REVISTAS PHILOSOPHIE MAGAZINE E FILOSOFIA CIÊNCIA \& VIDA}

A nossa análise partirá de uma reflexão sobre as formas de transmissão do discurso alheio empregadas pelos autores dos artigos de capa analisados. Em menor medida, também analisamos o emprego dos dêiticos pelos autores dos artigos de capa consultados. Essa análise tem como objetivo buscar respostas sobre a maneira como a filosofia é apresentada e representada nas revistas de divulgação da filosofia na França e no Brasil. Tendo em vista que as análises apresentadas serão discutidas de um ponto de vista sociológico - a transmissão do discurso alheio será observada conforme Volóchinov (2018 [1929]) -, julgamos relevante apresentar elementos contextuais sobre as duas revistas analisadas. Para isso, organizamos uma tabela, inspirada em Grillo e Glushkova (2016):

\begin{tabular}{|l|l|l|}
\hline \multicolumn{1}{|c|}{ Nome } & \multicolumn{1}{c|}{ Philosophie Magazine } & \multicolumn{1}{c|}{ Filosofia Ciência \& Vida } \\
\hline Editores & Editora Escala & Philo Éditions \\
\hline Lançamento & 2006 & 2006 \\
\hline $\begin{array}{l}\text { Tiragem } \\
\text { (exemplares/mês) }\end{array}$ & $\begin{array}{l}\text { França: } 37851 \\
\text { Exterior: } 5861 \\
\text { Total: 43 71212 }\end{array}$ & Não encontrado"13 \\
\hline Público-alvo & $\begin{array}{l}\text { "público curioso e } \\
\text { interessado, mas não } \\
\text { iniciado"14 }\end{array}$ & $\begin{array}{l}\text { "é uma publicação voltada tanto para } \\
\text { leigos quanto para iniciados e } \\
\text { interessados pelos estudos filosóficos } \\
\text { que aplica o tema ao nosso cotidiano } \\
\text { com uma proposta editorial } \\
\text { inovadora"15. }\end{array}$ \\
\hline
\end{tabular}

Tabela 1: Dados contextuais sobre as revistas $P M$ e $F C \& V$.

\subsection{Philosophie Magazine: o diálogo com o leitor presumido característico do discurso de divulgação científica}

Em vários momentos durante a leitura exploratória dos artigos de capa da revista Philosophie Magazine, observamos a necessidade dos autores em estabelecer um diálogo com o seu público-leitor. Uma análise mais aprofundada do uso dos dêiticos, bem como um estudo sobre a transmissão do discurso alheio, veio a confirmar essa nossa impressão. Vários são os casos de passagens nas quais os autores - que, notemos, são sempre jornalistas especializados na divulgação da filosofia e que compõem a equipe de redação da revista - estabelecem esse diálogo, que pode ser observado pelo emprego que fazem dos dêiticos:

12 Dados de 2018 da Alliance pour les chiffres de la presse et des médias. Disponível em: https://www.acpm.fr/Support/philosophie-magazine Acesso em: 06 jun. 2019.

13 Aguardamos resposta da ANER (https://www.aner.org.br/) e da IVC Brasil (https://ivcbrasil.org.br/\#/home) a esse respeito. Lembramos, ainda, que a revista faz parte do programa PNBE periódicos, cujo objetivo é a "aquisição e distribuição de revistas pedagógicas para auxiliar o trabalho dos professores da rede pública e do gestor escolar" : https://www.fnde.gov.br/programas/programas-do-livro/legislacao/item/9698-dados-estatisticos, acesso em: 28 nov. 2018.

14 No original: "public curieux et cultivé mais non initié". Disponível em: https://www.philomag.com/a-propos Acesso em: 29 abr. 2019.

${ }^{15}$ Disponível em: http://www.assinemais.com.br/assinemais/prod.asp?p=63\&cl=A63 Acesso em: 29 abr. 2019. 
(1) $\mathbf{J}^{16}$ 'ai peur. Vous avez peur. Nous avons peur... Nous vivons, semble-t-il, à une époque où la hausse tendancielle du niveau de la frousse fait loi. On va droit dans le mur, vous ne croyez pas? Regardez l'état des glaces de l'Arctique. La convalescence de l'économie mondiale. [...] $\left(P M, \mathrm{n}^{\circ} 34\right.$, nov. 2009, p. 36)

[Eu tenho medo. Você tem medo. Nós temos medo... Vivemos, ao que parece, numa época em que a alta tendencial do nível de frio na barriga é lei. A gente vai direto com a cara no muro, você não acredita? Olhe para o estado das geleiras do Ártico. A convalescência da economia mundial. [...]]

O autor utiliza, nesse excerto, o nós inclusivo, o que mostra que ele pensa a situação exposta junto com o seu leitor. Além disso, o uso do on (que traduzimos por "a gente"), nesse fragmento, conota leveza e dá um caráter mais informal à publicação francesa. Em geral, na escrita, não se utiliza a gente segundo a norma padrão da língua portuguesa, embora em francês esse pronome já tenha sido gramaticalizado. Nesse excerto, aliás, ele parece estar ligado a um uso equivalente ao da linguagem oral, pois o autor do artigo emprega um termo bastante coloquial um pouco antes: "la frousse", que, segundo o dicionário Le Grand Robert, é um termo coloquial para a palavra medo (frio na barriga). Por fim, ele se endereça diretamente ao leitor empregando o dêitico "vous", inclusive em sua forma imperativa ("regardez"), o que caracteriza uma conversa direta com o leitor. A partir de um determinado momento, pudemos notar que o nós inclusivo aparecia recorrentemente em perguntas dirigidas ao leitor, como no exemplo abaixo:

(2) Mais que faut-il faire? Avons-nous raison d'appliquer le principe de précaution ou devons-nous contempler avec méfiance le battage médiatique en cours ? Faut-il, avec Baudrillard, se faire les chantres de l'Apocalypse ou, au contraire, balayer ces élucubrations fatalistes? Avons-nous raison d'avoir peur? ( $P M, \mathrm{n}^{\circ} 34$, nov. 2009, p. 38)

[Mas o que se deve fazer? Temos razão de aplicar o princípio da precaução ou devemos contemplar com desconfiança o bombardeio midiático em curso? Deve-se, com Baudrillard, tornar-se anunciadores do Apocalipse ou, ao contrário, varrer para longe essas elucubrações fatalistas? Temos razão de ter medo?]

Embora uma análise baseada no emprego dos dêiticos, pelos autores dos artigos de capa de $P M$, possa ser de grande relevância para evidenciar o estabelecimento de um diálogo com o leitor em casos como o do exemplo acima, foi somente graças a um olhar dirigido para a maneira como se dava a transmissão do discurso alheio nos textos analisados que pudemos melhor compreender essa questão. Isso porque Volóchinov (2018 [1929]), quando apresenta a questão do discurso alheio na terceira parte de Marxismo e filosofia da linguagem (doravante MFL), fala justamente de uma transmissão desse discurso. Ou seja, aqui, a própria teoria nos faz voltar o olhar para esse diálogo com um terceiro:

Qualquer transmissão, principalmente se for fixa, possui objetivos específicos: um relato, um registro de uma sessão de júri, uma polêmica científica e assim por diante. Além disso, a transmissão é voltada para um terceiro, isto é, àquele a quem são transmitidas as palavras alheias" (VOLÓCHINOV, 2018 [1929], p. 252, grifo nosso).

${ }^{16}$ Utilizaremos o negrito para enfatizar os aspectos para os quais queremos chamar atenção. 
Agora, ao observamos a transmissão do discurso alheio no corpus francês - sobretudo observando essa transmissão a um terceiro, ou seja, ao leitor presumido das revistas -, uma questão que salta aos olhos é a presença, nos artigos de capa de $P M$, de um tipo específico de discurso relatado, classificado como "discurso direto substituído". Antes mesmo de abordar esse aspecto, Volóchinov (2018 [1929]) menciona a "importância sociológica" de todas as modificações de discurso direto do tipo retórico. Trata-se de uma modificação "persuasiva" (p. 285). O interesse dessas formas reside no fato de elas se situarem "bem na fronteira entre o discurso autoral e o alheio (normalmente interior)" (idem, ibdem, p. 285-286). O excerto abaixo, extraído de $P M$, parece-nos bastante ilustrativo:

(3) En 1974, l'astrophysicien britannique Brandon Carter formule le «principe anthropique », qui semble devoir réintroduire la question de la place de l'homme dans l'Univers au sein de la cosmologie contemporaine. Précisons immédiatement que le principe anthropique n'est pas le fruit de cerveaux superstitieux ni de cercles néoreligieux. C'est une hypothèse scientifique censée mieux nous faire comprendre la structure du réel. Mais ce nouveau concept nourrit depuis lors les disputes des cosmologistes. De quoi s'agit-il exactement ? D'un étonnement, né chez les scientifiques eux-mêmes en multipliant, depuis une cinquantaine d'années seulement, les confirmations expérimentales de la théorie du big bang. [...] (PM, $\mathrm{n}^{\circ}$ 9, maio 2007, p. 38)

[Em 1974, o astrofísico britânico Brandon Carter formula o "princípio antrópico", que parece ter que reintroduzir a questão do lugar do homem no Universo no seio da cosmologia contemporânea. Precisemos imediatamente que o princípio antrópico não é o fruto de cérebros supersticiosos nem de círculos neo-religiosos. É uma hipótese científica que supostamente nos faz melhor compreender a estrutura do real. Mas o novo conceito nutre desde então disputas entre os cosmologistas. Do que se trata exatamente? De um estranhamento, nascido nos próprios cientistas multiplicando, há uma cinquentena de anos somente, as confirmações experimentais da teoria do big bang. [...]]

A questão retórica "Do que se trata exatamente?" pode ser interpretada "simultaneamente como uma pergunta [...] do autor e como uma pergunta [...] do personagem [aqui, o leitor presumido da revista] direcionadas a si próprio" (VOLÓCHINOV, 2018 [1929], p. 286). Salientemos que o discurso alheio é definido como "o discurso dentro do discurso, o enunciado dentro do enunciado, mas também [como] o discurso sobre o discurso, o enunciado sobre o enunciado" (idem, ibdem, p. 249). Nesse sentido, se o autor faz a pergunta para em seguida respondê-la, como é o caso do exemplo (3), não teria por que fazê-la e respondê-la para si mesmo, caso não tivesse o intuito de expor o seu ponto de vista sobre uma determinada questão aos seus leitores. Nesse exemplo fica nítido, ainda, que o autor se faz uma imagem precisa do seu leitor presumido - trata-se de um leitor que, quando procura informar-se sobre astrofísica, espera encontrar respostas de fato científicas. Assim, o autor é ágil em ressaltar "imediatamente" que "o princípio antrópico não é o fruto de cérebros supersticiosos nem de círculos neoreligiosos". Vemos, desde já, que a observação desse diálogo com o leitor ser-nos-á de grande importância para respondermos à nossa questão maior de pesquisa, a saber: o modo como a filosofia é representada nas revistas de divulgação dessa disciplina, na França e no Brasil. Aqui, vemos que, no caso da ciência, dela é esperada reflexões mais exatas e menos especulativas, por exemplo. 
Um outro aspecto do discurso direto retórico que não abordamos até o momento é o fato de que esses discursos diretos não são colocados entre aspas. Segundo Volóchinov (2018 [1929], p. 287), "nessas perguntas e exclamações [...] prevalece, sem dúvida, a atividade do autor, e por isso elas nunca são colocadas entre aspas. Aqui fala o próprio autor, mas ele faz isso em nome do personagem, como se falasse no seu lugar". Vejamos outro exemplo:

(4) Nous serions donc confrontés à cette désolante symétrie : certains souffrent de ne pas avoir d'emploi, les autres, de travailler. Une telle description serait-elle exagérée ? Sans doute, mais les chiffres disponibles sur le sujet son alarmantes. (PM, $\mathrm{n}^{\circ} 39$, maio 2010, p. 36)

[Nós seríamos então confrontados a essa simetria desoladora: alguns sofrem por não ter emprego, outros, por trabalharem. Uma tal descrição seria exagerada? Sem dúvida, mas os números disponíveis sobre o assunto são alarmantes.]

Muitas vezes, na transmissão do discurso direto retórico, "o autor se antecipa ao seu personagem, fala por ele aquilo que ele poderia ou deveria dizer, que convém à situação" (VOLÓCHINOV, 2018 [1929], p. 287). Esse é o discurso direto substituído: é "[e]ssa fala no lugar do outro [que] se aproxima muito do discurso indireto livre" (idem, ibdem, p. 287). No caso do exemplo acima, vemos claramente que o autor do artigo de capa de $P M$ se antecipa a uma possível objeção do seu leitor. Embora tal afirmação pareça exagerada, ele demonstrará, nas linhas seguintes, que não. E aqui entra em cena a filosofia propriamente dita: é ela que virá como resposta, conforme vemos no exemplo abaixo:

(5) $[\ldots]$ L'anthropomorphisme semble naturellement s'allier à l'anthropocentrisme, cette propension à toujours imaginer l'homme au centre de l'Univers, et qui a été si sévèrement réfutée. Faut-il en conclure que le principe anthropique n'est qu'une artificielle volonté de réenchantement du monde, le dernier hoquet d'un finalisme moribond ? [§] Non, car Freud n'a pas tout à fait raison d'affirmer que la science a humilié l'homme en le décentrant. L'histoire de nos représentations de l'Univers ne saurait se résumer de manière aussi schématique. Revenons aux premières cosmologies de l'Antiquité. Lorsqu'Aristote, quatre siècles avant notre ère, propose une théorie $[\ldots]\left(P M, \mathrm{n}^{\circ} 9\right.$, maio 2007, p. 40)

[[...] $\mathrm{O}$ antropomorfismo parece aliar-se naturalmente ao antropocentrismo, essa propensão a sempre imaginar o homem como centro do Universo, e que foi tão severamente refutada. Deve-se concluir que o princípio antrópico não é que uma vontade artificial de reencantamento do mundo, o último soluço de um finalismo moribundo? Não, pois Freud não tem completamente razão ao afirmar que a ciência humilhou o homem descentrando-o. A história de nossas representações do Universo não saberia se resumir de maneira tão esquemática. Retornemos aos primeiros cosmólogos da Antiguidade. Quando Aristóteles, quatro séculos antes da nossa era, propõe uma teoria [...]]

Notamos, no excerto acima, que todo o diálogo parece servir para conduzir o leitor à apresentação da própria filosofia, convencendo-o do interesse desta como disciplina, de sua relevância. Logo após o discurso direto substituído - quando o autor apresenta uma questão -, já é oferecida uma resposta. É interessante notar, também, o uso da terceira pessoa em "revenons" (retornemos): vê-se claramente que o autor "pega pela mão" o seu leitor-presumido, 
conduzindo-o pela argumentação de maneira bastante didática. O exemplo (5), assim como todos os exemplos apresentados nesta seção, bastante representativos da forma de se divulgar a filosofia na revista $P M$, mostra que os artigos da revista francesa apresentam um perfil de jornalismo científico:

[...] o jornalista científico pertence a uma esfera de atividade linguageira "intermediária", que se situa entre a esfera de atividade "erudita", dos especialistas [aqui, os filósofos] [...] e a esfera de atividades dos leitores comuns [...] [interessados em filosofia], fato que se traduz em um discurso (o discurso do jornalista) cujo intertexto (MOIRAND, 2000; REBOUL-TOURÉ, 2000) retoma sucessivamente as perguntas dos leitores e as respostas presentes no discurso da esfera de atividades [dos filósofos, nesse caso] [...] (MOIRAND; REBOUL-TOURÉ; RIBEIRO, 2016, p. 149 [grifo nosso])

Moirand, Reboul-Touré e Ribeiro (2016) estudam a transmissão do discurso alheio como uma forma de dialogismo interacional, que revelaria uma intenção de “didaticidade” (p. 149). É o que se percebe no exemplo (5) acima. Uma de nossas questões, na nossa pesquisa de pósdoutorado, é saber se a divulgação da filosofia dar-se-ia da mesma forma que a divulgação científica propriamente dita, das disciplinas exatas. Na revista francesa parece que sim, mas esse não parece ser o caso da revista brasileira, conforme apresentaremos na seção 4.2 abaixo. As análises apresentadas nesta subseção tiveram como foco principal o "intuito discursivo, isto é, [quais] as razões de um enunciado [no caso, os enunciados das revistas analisadas] reportar ou evocar outro em determinado contexto enunciativo e sócio-histórico-cultural" (LUNA; CUNHA, 2018, p. 170). É essa a perspectiva sociológica, que não havíamos explorado em pesquisas anteriores, e para a qual

[...] é preciso compreender o porquê de certo discurso ser reportado pelo autor, em dada situação; o modo como ele é percebido pelo(s) destinatário(s), em dado contexto receptivo; as réplicas interiores e reações verbais que ele suscita; o conteúdo que ele carrega e a forma como ele é representado (as modificações sintáticas, estilísticas e composicionais que ocorrem na sua própria construção e no enunciado autoral que o incorpora). (LUNA; CUNHA, 2018, p. 171)

Na nossa tese, por exemplo (SARDÁ, 2015), empregamos a representação do discurso outro como uma das categorias de análise do nosso corpus, seguindo a teoria de Auhtier-Revuz, cuja análise não é sociológica, mas "uma análise do ponto de vista da língua", conforme esclarecem Luna e Cunha (2018, p. 173). Continuaremos explorando essa questão no corpus brasileiro na seção abaixo.

\subsection{Filosofia Ciência \& Vida: uma revista majoritariamente escrita por acadêmicos em diálogo com seus pares}

Em alguns números de $F C \& V$ os artigos de capa são escritos por jornalistas, principalmente nos dois primeiros anos de circulação da revista no Brasil (2006 e 2007). É o caso do número 3, por exemplo, publicado no primeiro ano da revista. No exemplo abaixo, a jornalista articula as vozes de alguns professores de filosofia sobre o que dizem os filósofos. Essa forma de transmitir o discurso alheio (da filosofia, no caso) é um tanto reveladora do universo dos jornalistas divulgadores da filosofia no Brasil. De um ponto de vista sociológico, poderíamos nos perguntar se não há profissionais interessados nesse ramo do jornalismo no Brasil, ou, o que é mais provável, se não há espaço para esse tipo de trabalho ainda. Vejamos o exemplo: 
(6) Professor da Universidade Católica de Santos e do Centro Universitário Monte Serrat e mestre em Lógica e Filosofia da Linguagem pela Pontifícia Universidade Católica de São Paulo, Fabio Cardoso Maimone explica que, dentro dos temas da Filosofia, o amor é um dos mais importantes sentimentos. "Até mesmo na palavra Filosofia há relação com este sentimento: amor pela sabedoria. Sofia é sabedoria e Filia é um tipo de amor, que não é carnal, mas o amor da busca, do desejo; é o amor da inquietação". $O$ amor do amigo. $\left(F C \& V\right.$, ano I, $\mathrm{n}^{\circ} 3$, out. 2006, p. 17)

Nota-se que o discurso direto, aqui, é oriundo de uma entrevista realizada com um professor universitário. A jornalista mantém uma distância em relação a esse enunciado, pois ele é transmitido após a apresentação do currículo do professor. Aqui, o itálico representa a entonação do que foi dito pelo professor. O mesmo ocorre no número 7 , cujo tema abordado é a obrigatoriedade do ensino da filosofia nas escolas:

(7) "Há muitas razões para todo esse entusiasmo", diz Marino Antônio Sehnem, professor do departamento de Teologia da Pontificia Universidade Católica de São Paulo (PUC-SP). Filósofo com formação em Letras e Pedagogia, Sehem ressalta a sabedoria milenar que trata o ser humano na sua totalidade. "Está na essência da Filosofia ser um instrumento atuante de diálogo entre saberes", afirma. ( $F C \& V$, ano I, n ${ }^{\circ}$ 7, fev. 2007, p. 25-26)

Vemos, nesse exemplo, o valor dado à transmissão da palavra do professor de filosofia da PUC, o qual, além de ser formado em filosofia, também o é em letras e em pedagogia; títulos que o autorizam a tratar de temas relativos à esfera da educação. A revista brasileira tem um público voltado para a esfera escolar e é distribuída nas escolas, das quais depende para existir; ao contrário da França, onde existem condições sociais, materiais e institucionais para a circulação de uma revista de filosofia voltada ao grande público. Assim, tudo indica que os editores de $F C \& V$ passaram a convidar diretamente os acadêmicos para escrever esses artigos de capa (é o que acontece nos números do nosso corpus, publicados a partir do terceiro ano de circulação dessa revista). Aliás, esse foi um dos primeiros aspectos que nos chamou a atenção nas revistas brasileiras: as referências à palavra do outro são em sua maioria apresentadas detalhadamente, conforme as regras acadêmicas de citação:

(8) Em sua III Consideração Intempestiva - Schopenhauer como educador, Nietzsche compreende treze características que norteiam a tipologia do erudito, sendo possível sintetizá-la desta maneira: “(...) o erudito consiste numa rede misturada de impulsos e excitações muito variadas, é um material impuro por excelência"* [ ${ }^{*} E m$ nota de rodapé: NIETZSCHE, 2003, p. 191]. ( $F C \& V$, ano VI, nº 67, fev. 2012, p. 15-16) ${ }^{17}$.

\footnotetext{
${ }_{17}$ Observamos que os artigos de capa da revista francesa $P M$ são marcados pela ausência de precisão sobre o ano e a página das obras cujos discursos aparecem em forma de citação. Uma exceção notável ocorre quando o autor torna precisa as edições disponíveis de uma determinada obra, como é o caso do seguinte exemplo: "L'attention est affaire 'd'échantillonnage', précise Jean-Phillipe Lachaux dans Le Cerveau attentif (Odile Jacob, 2013 ; nouv. éd. 2015) : la capacité du cerveau à extrapoler lui permet de programmer son attention dans le temps. Cela permet de s'assurer que l'attention est la plus intense possible au moment opportun". (PM, $\mathrm{n}^{\circ} 88$, abr. 2015, p. 45) [“A atenção é questão de 'amostragem', precisa Jean-Phillipe Lachaux em $O$ Cérebro atento (Odile Jacob, 2013; nova edição 2015): $a$ capacidade do cérebro em extrapolar lhe permite programar sua atenção no tempo. Isso permite garantir que a atenção é a mais intensa possivel no momento oportuno".]
} 
Ao final do artigo, há uma seção com todas as referências utilizadas no texto. O excerto acima é parte de um artigo de capa sobre Nietzsche e a educação. Para escrever sobre o tema, foi convidado um acadêmico que realizava o mestrado em Ciências da Educação na Universidade Estadual de Londrina. Vemos em (8) um discurso em estilo linear: as fronteiras entre o discurso autoral e o discurso alheio estão bem sinalizadas com o emprego das aspas, o que confirma a sua autenticidade (reforçada com a menção à obra concreta da qual a citação foi extraída). Podemos afirmar que a filosofia é valorizada na revista brasileira, no sentido de que é atribuído àquela um valor de autoridade. $\mathrm{O}$ que também é o caso na revista francesa, mas sem essa preocupação acadêmica: é próprio da esfera acadêmica que as citações sejam precisas, pois um artigo acadêmico deve permitir que o leitor - ele mesmo um acadêmico - possa refazer o percurso de leitura apresentado pelo autor, a fim de verificar a consistência dos argumentos apresentados.

No número 85, de agosto de 2013, a mesma estrutura de textos acadêmicos pode ser mais claramente observada. $\mathrm{O}$ autor do artigo não somente cita os autores em detalhes, como ainda faz uma associação de duas citações sobre um mesmo tema (o que é característico da revisão bibliográfica de conceitos feita na Academia):

(9) Conforme aponta Walter Benjamin (1892-1940), a afirmação de que os fins da violência policial seriam sempre idênticos aos do reino do Direito, ou pelo menos teriam relação com estes, é inteiramente falsa. Pelo contrário, o "Direito" da polícia assinala o ponto em que o Estado, seja por impotência, seja por causa das conexões imanentes a qualquer ordem de direito, não consegue mais garantir, por meio dessa ordem, os fins empíricos que ela deseja alcançar a qualquer preço*. [*Em nota de rodapé: BENJAMIN, Para uma crítica da violência. In: Escritos sobre mito e linguagem, p. 135.] [...] Conforme argumenta o sociólogo francês Loïc Wacquant (1960), essa violência policial se inscreve em uma tradição nacional multissecular de controle dos miseráveis pela força, tradição originada da escravidão e dos conflitos agrários, que se viu fortalecida por duas décadas de ditadura militar, quando a luta contra a "subversão interna" se disfarçava em repressão aos delinquentes*. [*Em nota de rodapé: WACQUANT, As prisões da miséria, p. 11] (FC\&V, no 85 , ago. 2013, p. 19)

No exemplo acima, as referências aparecem em notas de rodapé, como no sistema de citação mais corrente na área de filosofia (que não costuma utilizar o sistema autor-data, como nas exatas) e, ao final do texto, todas as referências aparecem detalhadamente na seção "Referências".

Já o artigo de capa do número 32 de $F C \& V$ foi redigido por Scarlett Marton, professora titular de filosofia da Universidade de São Paulo. Era de se esperar, portanto, que a autora empregasse uma grande quantidade de citações detalhadas, como no exemplo acima, mas esse não é o caso. A autora preocupa-se em divulgar as ideias de Nietzsche citando outros filósofos como Descartes e Bacon de forma mais livre, sem precisar as obras ou as páginas de cada citação. Citações que são bastante curtas e muito mais "expressões" ditas por cada um dos filósofos:

(10) Mas é somente nos tempos modernos que se passa a pensar vida e morte como nitidamente opostas. E isto não causa surpresas. Com a modernidade, aprofundam-se velhos dualismos e novos se instauram. Nós, "senhores e possuidores da natureza", como dizia René Descartes (1596-1650), nos afastamos do mundo e dele nos diferenciamos. Entendendo que "saber é poder", como dizia Francis Bacon (1561-1626), ao mundo nos opomos e 
sobre ele queremos exercer nosso controle e domínio. Nós nos convertemos em sujeito e, pelo mesmo movimento, convertemos tudo o mais em objeto. Apreendemos o que existe como aquilo sobre o qual podemos ter ideias; captamos o próprio mundo como se ele apenas existisse na medida em que pudéssemos representá-lo. ( $F C \& V, \mathrm{n}^{\circ} 32$, mar. 2009, p. 20).

Se atentarmos para o emprego dos dêiticos, vemos que há uma presença marcada do "nós" inclusivo. No entanto, o uso desse dêitico é diferente do emprego feito dele pelos jornalistas franceses, nas edições comentadas mais acima. Aqui, temos o emprego de uma série de "nós" genéricos, associado ao apagamento enunciativo, como vimos na nossa tese de doutorado. $\mathrm{O}$ excerto (10) estaria, a nosso ver, a meio caminho entre os exemplos dos divulgadores franceses (seção 4.1 acima) e os exemplos mais acadêmicos vistos nesta seção, como em (8) e (9). Um dado interessante apresentado por Oliveira (2015) é a existência de uma grande discussão na academia em torno da divulgação das ideias de Nietzsche, que teria aspectos positivos e negativos (cf. p. 12 e 13). Certamente a acadêmica Scarlett Marton estava a par dessas discussões, que tiveram influência na redação de seu texto para a revista $F C \& V$. Salvo esse exemplo em particular, observamos que a divulgação da filosofia no Brasil ainda é bastante atrelada às instituições, o que justifica a formalidade com a qual ela é tratada, tal como vimos nas análises feitas até aqui. Tendo exposto separadamente a análise dos corpora francês e brasileiro, nas seções acima, exporemos, logo abaixo, algumas interpretações acerca dos resultados aos quais chegamos na conclusão deste artigo.

\section{CONCLUSÃO}

Os resultados das análises comparativas das revistas de divulgação da filosofia condizem com o que é dito pelos editores acerca do público-alvo de cada revista: $P M$ tem como públicoalvo não iniciados em filosofia, enquanto $F C \& V$ trabalha com os dois públicos: iniciados e leigos. Essa diferença de público é marcada pelas escolhas léxico-gramaticais (como o emprego do "on" nas revistas francesas, o qual reveste estas de um caráter mais informal), enquanto que a revista brasileira é marcada por escolhas mais acadêmicas. Mas o interessante das análises efetuadas é que elas mostram o processo de construção dos discursos em ambas as revistas: na França, parece haver um mercado mais propício - constatado nos discursos da revista $P M-$ de divulgadores especializados (jornalistas) em filosofia, enquanto que no Brasil o mesmo não ocorre. Analisando somente os discursos dos artigos de capa, sabemos que essas diferenças não se devem às características de um determinado gênero discursivo, mas a fatores culturais que refletem as diferentes concepções da divulgação da filosofia, na França e no Brasil.

$\mathrm{Na}$ perspectiva dialógica da divulgação científica, adotada neste estudo, os traços que caracterizam o discurso de divulgação envolvem o desejo, por parte dos divulgadores, de "ampliação do estado de saberes de uma área em particular [...] [e com o aumento do] estado de conhecimento do seu público-alvo, sem, contudo, incorporá-lo enquanto agente do campo científico, submetendo seus saberes a uma resposta avaliativa-crítica" (GRILLO, 2013, p. 13). Nesse sentido, a revista francesa apresenta os traços característicos do discurso de divulgação científica, conforme apontado nas análises acima. Já a revista brasileira amplia os saberes dos leitores relativos à filosofia, incorporando em alguma medida o leitor nessa discussão, por meio de citações acadêmicas, como um possível "agente do campo científico".

Na tabela apresentada no início da seção 4, vê-se que a revista francesa tem uma tiragem bastante elevada, inclusive contando com um público internacional. Já no caso da revista 
brasileira, trata-se de uma tiragem certamente menor (ainda não temos os números oficiais) e muito voltada à esfera escolar - tanto que a revista é distribuída nas escolas por um programa do Ministério da Educação. Dessa forma, levantamos a hipótese de que, no país, ainda não se criou um espaço propício ao surgimento de divulgadores da filosofia mais especializados, o que requer um mercado consumidor para esse tipo de publicação, que ainda não temos no Brasil por diversas razões sócio-econômicas e culturais, como o grau de letramento da maioria da população. Podemos, além disso, voltar a um ponto discutido na nossa tese (SARDÁ, 2015), quando verificamos uma tendência mais forte, na comunidade brasileira, em perceber a filosofia como uma disciplina inútil e pouco rentável economicamente. Donde o surgimento de um discurso de reação nas revistas brasileiras, as quais sempre enfatizam o(s) título(s) acadêmico(s) dos autores, como uma maneira de legitimar o trabalho realizado nessa área. Por fim, na nossa tese vimos também que o ensino da filosofia no Brasil ainda é marcado por certo "conteudismo", o que também não favorece a curiosidade por esse tema por parte de estudantes que poderiam vir a ser um público-consumidor desse tipo de revista de divulgação.

Ressaltamos, todavia, que, para responder a nossa questão mais geral sobre as representações da filosofia na França e no Brasil, pretendemos, ainda, ampliar o corpus analisado (observando, por exemplo, outros gêneros no interior das revistas, como o editorial) e cruzar as análises apresentadas com a análise baseada em outras categorias conceituais, como uma observação mais atenta das relações dialógicas estabelecidas nos artigos de capa das revistas, por exemplo.

\section{$\overline{\text { REFERÊNCIAS }}$}

BRAIT, B. Análise e teoria do discurso. In: p. 9-31.

(Org.). Bakhtin: outros conceitos-chave. São Paulo: Contexto, 2018.

CLAUDEL, C.; VON MÜNCHOW, P.; PORDEUS RIBEIRO, M.; PUGNIÈRE-SAAVEDRA, F.; TRÉGUER-FELTEN, G. Langue, discours et culture: déchiffrer les formes du vivre ensemble. In: Nouveaux abordages. Limoges: Lambert-Lucas, p. 15-45, 2013.

(Org.). Cultures, discours, langues.

COMBETTES, B. Discours rapporté et énonciation : trois approches différentes, Pratiques, nº 64, dez. 1989. p. 111 -122.

DICIONÁRIO ELETRÔNICO LE GRAND ROBERT DE LA LANGUE FRANÇAISE. Paris: Le Robert, 2005.

GRILlo, S. V. de C. Divulgação científica: linguagens, esferas e gêneros. Tese de livre-docência. São Paulo: Universidade de São Paulo, 333 f., 2013.

GRILLO, S. V. de C.; GIERING, M. E.; MOTTA-ROTH, D. Perspectivas discursivas da divulgação/popularização da ciência, Bakhtiniana, 11 (2), São Paulo, p. 3-13, 2016.

GRILlO, S. V. de C.; GLUSHKOVA, M. A divulgação científica no Brasil e na Rússia: um ensaio de análise comparativa de discursos, Bakhtiniana, nº 11 (2), São Paulo, p. 69-92, 2016.

LUNA, T. S.; CUNHA, D. de A. C. da. O discurso outro em narrativas ficcionais e não ficcionais, Linha D’Água, São Paulo, v. 31, n. 3, p. 167-190. set./dez. 2018.

MAINGUENEAU, D. Trouver sa place dans l'enceinte philosophique : penseurs, gestionnaires, passeurs, Argumentation \& Analyse du Discours, $\mathrm{n}^{\circ} 22,2019, \mathrm{n} / \mathrm{p}$.

MOIRAND, S.; REBOUL-TOURÉ, S.; RIBEIRO, M. P. A divulgação científica no cruzamento de novas esferas de atividade linguageira, Bakhtiniana, São Paulo, 11 (2), p. 145-171, maio/ago. 2016. 
MÜNCHOW, P. von. Le discours sur les conflits entre nations dans les manuels d'histoire français et allemands. Représentations de la Première Guerre mondiale. In: GONNOT, A.-C.; RENTEL, N.; SCHWERTER, S. (Org.). Dialogues entre langues et cultures. Francfort-sur-le-Main: Peter Lang Édition, p. 85-106, 2013.

OLIVEIRA, G. M. V. de S. Da popularização da filosofia à expertise filosófica: uma problematização do papel do intelectual na mídia (revista Cult 1997-2013). Dissertação de mestrado, Universidade de São Paulo, 2015, 189 p.

RASTIER, F.; PINCEMIN, B. Des genres à l'intertexte, Cahiers de praxématique, 33, p. 83-111, 1999.

SARDÁ, D. N. A análise de discursos comparativa no Brasil: uma reflexão a partir da noção de categoria, Bakhtiniana, São Paulo, v. 16, nº 2, mar. 2021 [aceito para publicação].

SARDÁ, D. N. Les manuels de philosophie en France et au Brésil. Une analyse du discours contrastive de la prise en charge énonciative. Tese de doutorado. Paris: Université Paris Descartes/ Sorbonne Paris Cité, 316 f., 2015.

VOLÓCHINOV, V. Marxismo e filosofia da linguagem. Problemas fundamentais do método sociológico na ciência da linguagem. São Paulo: Editora 34, 2018 [1929]. Trad. Sheila Grillo e Ekaterina Vólkova Américo.

Recebido: 6/7/2020

Aceito: $7 / 1 / 2021$

Publicado: $14 / 1 / 2021$ 